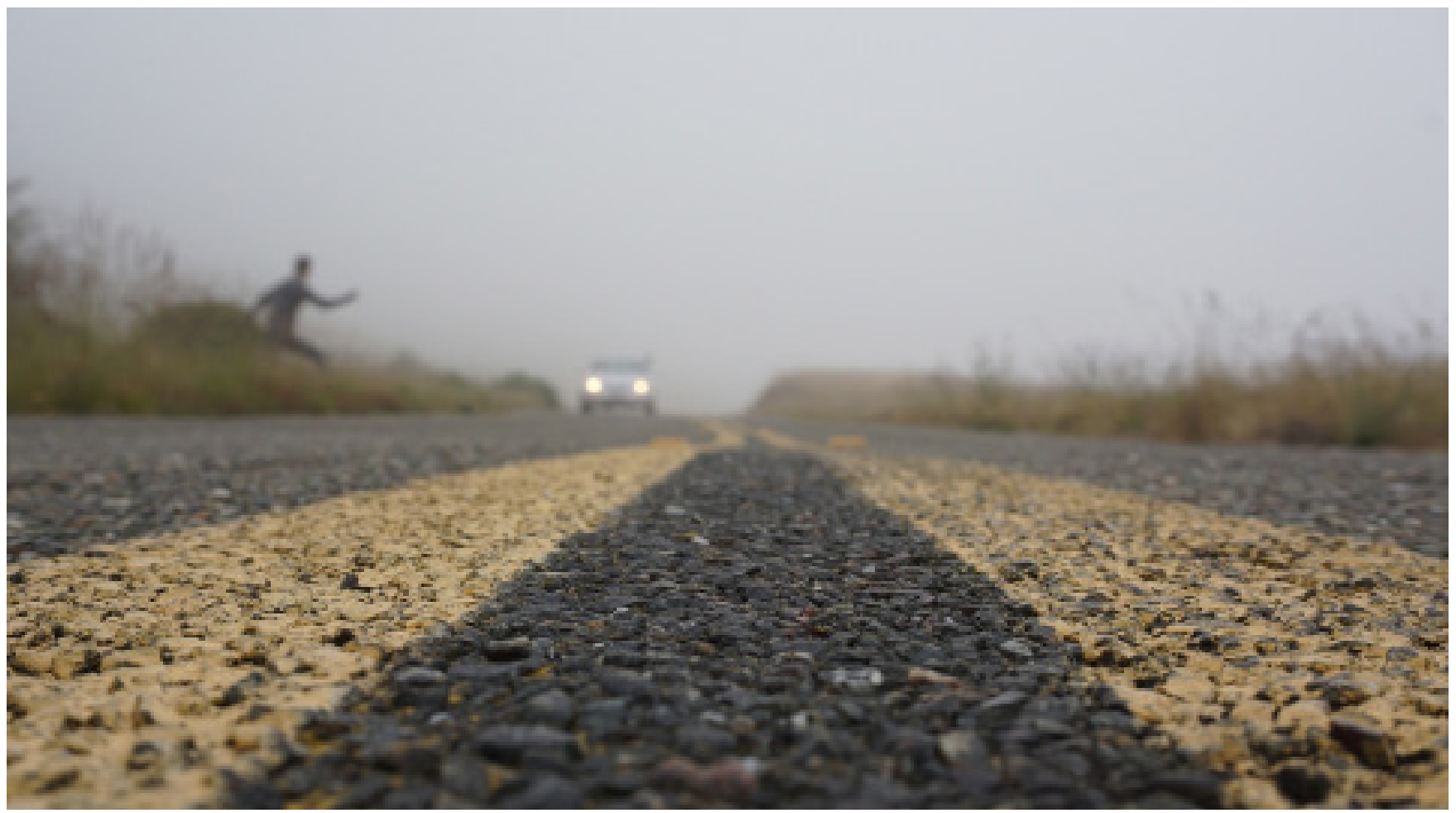

\title{
Pavimento flexible utilizando una mezcla asfáltica con grano de caucho reciclado para su sostenibilidad en Colombia
}

\section{Flexible pavement using an asphalt mixture with recycled rubber grain for its sustainability in Colombia}

Maríalejandra Cardoza-Zambrano

Estudiante Ingeniería Civil, mariacardoza2@gmail.com, Universidad Francisco de Paula Santander. Cúcuta, Colombia

Karol Vanessa Palomino-Cadena

Estudiante Ingeniería Civil, karolpalomino1@gmail.com, Universidad Francisco de Paula Santander. Cúcuta, Colombia
Gina Ester Angulo-Blanquisett

Ingeniero Civil, gina.angulo@utadeo.edu.co,

https://orcid.org/0000-0001-5020-1933, Universidad Jorge Tadeo Lozano, Cartagena de Indias, Colombia 


\section{Resumen}

El objetivo principal de la investigación fue recabar información sobre el grano de caucho que se recicla y cómo es usado en las mezclas de asfalto en Colombia, donde se ha implementado mostrando grandes avances por sus beneficios ambientales y económicos, esta investigación se basó en un modelo descriptivo y documental, por cuanto se revisaron documentos donde se realizaron pruebas con estos materiales y analizar los resultados de ellos. Se evidencia la importancia de la aplicación de esta tecnología innovadora como un recurso que se puede implementar a los problemas de tipo mecánico que son muy frecuentes en el pavimento flexible y de la misma manera, reducir los problemas de impacto ambiental que genera la gestión inadecuada de las llantas desechadas una vez culminada su vida útil.

Palabras clave: Impacto ambiental,

\section{Abstract}

The main objective of the research was to gather information about the rubber grain that is recycled and how it is used in the asphalt mixtures in Colombia, where it has been implemented showing great advances due to its environmental and economic benefits. This research was based on a descriptive and documentary model, as documents were reviewed where tests were carried out with these materials and the results were analyzed. It is evident that the application of this innovative technology is a resource that can be implemented to the mechanical problems that are very frequent in flexible pavements and, in the same way, reduce the environmental impact problems generated by the inadequate management of discarded tires once their useful life is over.

Keywords: Environmental impact, recyclable material, flexible pavement. 
Introducción

A nivel mundial, las vías son la parte fundamental para el progreso de un país social y económicamente, ya que por medio de éstas las poblaciones se comunican entre ellas mismas para el intercambio de productos y servicios entre comunidades para un mejor común [1].

La dependencia entre la disponibilidad de vías de comunicación terrestre y el nivel de desarrollo de la población son objeto de extensos números de estudios; dado que éstas permiten el desarrollo de un país, por tanto, las vías deben estar en óptimas condiciones en su funcionamiento, lo cual conlleva a practicar numerosos estudios ya sean para su avance o mantenimiento constantemente para una efectiva comunicación entre poblaciones. Contar con un mayor acceso de carreteras facilitan la movilidad de las personas hacia otros lugares y permitiendo aumentar y mejorar los intercambios económicos de las regiones [2].

Es por esta razón que el diseño de un pavimento necesita tener en cuenta las cargas suministradas que genera el tránsito, las cuales pueden ocasionar deformaciones sobre está e incluso afectar directamente a la subrasante en un pavimento. Actualmente existe un pavimento (pavimento flexible) que durante años sea implementado y que a pesar de tener falencias ha permitido soporté de cargas y resistencia a estas de manera eficiente; se define como una estructura vial conformada por una capa asfáltica apoyada sobre capas de menor rigidez, compuesta por materiales granulares (base, subbase, bases mejoradas), que a su vez es soportada por el suelo natural (subrasante) [3].

Además, este pavimento se caracteriza por estar integrado por capas bituminosas apoyándose con otras interiores, por lo tanto, la capa superior será la que posee la mayor capacidad de carga de material (la más costosa) y la última capa tendrá menos capacidad de carga de material (menos costosa) [4]; es decir que la inversión que se le hace a cada capa corresponde a la magnitud de carga que va soportar cada una de ellas, por eso, en ciertos casos no es prescindible el uso de todas las capas porque muchas veces estás no tiene un funcionamiento fundamental en la estructura del pavimento.

No obstante, este tipo de asfaltos (convencional) utilizados en la construcción tienen propiedades y características que en la actualidad no son suficientes para satisfacer las necesidades debido al incremento de flujo vehicular [5]; El reciclaje de pavimentos flexibles a la reutilización, generalmente después de cierto tratamiento, de un material de pavimento que ha concluido con su finalidad, y este material reciclado puede emplearse para construcción en refuerzos de la misma carretera o alguna capa de una calzada nueva [6]; de lo anterior se observó que los recursos reciclables sirven como alternativa para el refuerzos de pavimentos ya que mejoran sus propiedad brindando mayor resistencia a la carpeta asfáltica, disminución de mantenimiento de la vía, durabilidad y mayor soporte.

Por otro lado, el reciclaje se puede establecer como un método de varias materias primas que se integran para moldear otros materiales donde se utilizan en la vida diaria y por medios de ciclos de usos vuelven a convertirse en otros materiales [7]; Este es importante ya que ayuda reutilizar los materiales que han culminado su ciclo de vida y a su vez a disminuir la contaminación que cada uno de ellos provocan en el ambiente, entre estos materiales uno de los que más impacto ambiental tiene es el caucho. Como se conoce el neumático es uno de los recursos que más contaminan el medioambiente debido a que 


\section{0}

una vez terminada su ciclo productivo, pasa a ser un agente obsoleto para su fin inicial. Ante esto los desechos de los neumáticos cada vez más son desechados mass habitualmente en donde no existe ningún registro sobre estos acontecimientos ni en lugares preparados para depositarlos sin que afecte otros contextos. Según reportes derivados de proyectos para el aprovechamiento de llantas de desecho, promovidos por el Instituto Nacional de Ecología (INE), cada neumático tarda 500 años en biodegradarse, es por ello que existe la totalidad de lkos que han fabricado sin saber cuál ha sido su disposición final [8]. Actualmente nmo existen empresas que se dedican a este tipo de procesamiento, son muy pocas y es allí donde se hace necesaria la reutilización de estos materiales [9].

Actualmente el $72 \%$ de las llantas fuera de uso se utilizan como fuente energética en los hornos industriales e incluso en los de la industria alimenticia tipo trapiche de caña de azúcar, contribuyendo a contaminar la atmósfera del planeta, destruyendo la capa de ozono, ocasionando efecto invernadero y en todo el país las llantas fuera de uso se han convertido en un problema ambiental y de salud pública toda vez que solamente entre el $2 \%$ y el $3 \%$ de ellas están siendo utilizadas en unos pocos centros de reciclaje a nivel nacional [10]; con lo anterior es notable la afectación que producen este recurso para el ambiente y para la salud de la comunidad, por tanto la idea de reutilización es necesaria y positiva para mitigar lo mencionado con anterioridad.

Por tanto, [11] el grano de caucho reciclado es uno de los nuevos recursos que se utilizan para brindar la resistencia necesaria en un pavimento flexible y mejorar su sostenibilidad, este recurso es asequible ya que una vez culminada su vida útil se vuelve obsoleto $\mathrm{y}$ dañino para el medio ambiente; gracias a esto no genera costos al momento adquirirlo y solamente me crearía presupuesto cuando vaya hacer procesado, esta implementación me aporta al medio ambiente debido que su escala de contaminación es alta, ya que la mayorías de las personas una vez finalizada su utilidad proceden a la quema de esté, lo que representa emisiones de $\mathrm{CO} 2$ en el ambiente.

Es conveniente la implementación del Grano de Caucho Reciclado (GCR) debido a que traen beneficios físico-mecánicos al asfalto brindando un mejor funcionamiento a la infraestructuras vial [12]; y al mismo tiempo favorece al medio ambiente, ya que las llantas generan gran impacto ambiental debido a su corta vida útil (45.000 kilómetros) [13]; Habría que decir también que los inadecuados procesos de disposición final que se aplican sobre el recurso son: el abandono, almacenamiento en basureros, acumulación o quema a cielo abierto de manera incontrolada; originando problemas de contaminación de lasaguas, suelos, espacios públicos(lagos, ríos, calles y parques) con graves consecuencias en términos ambientales, económicos y sanitarios.

Finalmente, las acumulaciones de neumáticos forman arrecifes donde la proliferación de roedores, insectos y otros animales portadores de enfermedades constituye un problema para la salud. La reproducción de ciertos mosquitos, que transmiten por picadura fiebres y encefalitis, llega a ser 4.000 veces mayor en el agua estancada de un neumático que en la naturaleza [11], de acuerdo a esto el aporte medioambiental es mucho mayor al que causa en la carpeta asfáltica por esta razón reduce las posibles afección de salud a las que se ven expuesta la comunidad. Sin embargo, existen otras alternativas de asfalto modificado que pueden brindar beneficios similares al del pavimento flexible con grano de caucho reciclado, como es el caso de cenizas volante, el tamo y otros biomateriales. El propósito de esta investigación fue identificar los beneficios del grano de caucho reciclado para una mezcla asfáltica en pavimentos flexibles, indagar sobre las características del grano de caucho reciclado sobre el pavimento 
flexible, para analizar el impacto del uso del pavimento flexible con el grano de caucho reciclado y estimar los beneficios del grano de caucho reciclado para una mezcla asfáltica en pavimentos flexibles.

La realización de este proyecto tiene una gran importancia en el sector productor de mezclas asfálticas, ya que la implementación de este tipo de mezcla presenta otra opción en la construcción de las vías que se requieren mejorar. Por consiguiente, el producto que se ofrece responde a la deficiencia actual de la infraestructura vial que afecta al transporte de carga, la cual reduce la competitividad logística del país. En Colombia, además de las minería, petróleo y agricultura "la mayoría de los sectores requieren una movilidad más eficiente del transporte de carga ya que, un $80 \%$ del transporte se mueve de carretera hacia los puertos y las zonas fronterizas" [14].

La afirmación anterior puede generar beneficios para la empresa, debido a la rentabilidad que puede recibir, así como reducción de sobrecostos que enfrentan los transportadores de carga ya que, en malas condiciones viales en las que transitan las tracto-mulas, las transportadoras pagan un sobrecosto de un $35 \%$. Por otro lado, en el aspecto ambiental tendrá un alto grado de importancia, ya que el elemento fundamental para la empresa es el GCR, el cual se obtiene al triturar el neumático, por esta razón una vez culminada su vida útil queda a la intemperie por ser un material no biodegradable [14].

Se puede señalar que la infraestructura de transporte es de gran importancia para el crecimiento y desarrollo de un país. El $80 \%$ De la carga en Colombia se moviliza por carretera y durante los últimos 30 años se ha incrementado el número y la magnitud de carga, es por esta que la utilización de mezclas asfálticas mejoradas con caucho son una realidad hoy en Bogotá, debido al incentivo de instituciones como el IDU, el ministerio de ambiente y desarrollo territorial, el siguiente paso será sin duda la utilización de estas mezclas en toda Colombia a través del apoyo de instituciones como el instituto nacional de Invias y el instituto de concesiones INCO [15].

Finalmente, el desarrollo que ha tenido el manejo de las llantas generan beneficios sociales y económicos, dado a que crean oportunidades de negocio y empleo particularmente para las personas naturales 0 jurídicas que se dediquen a la gestión final de las llantas desechadas para la obtención de GCR; desde el punto de vista técnico se evidencian ventajas a corto y largo plazo; puesto que, a corto plazo al aplicarlo a la mezcla asfálticas sobre la vía, ocasiona elasticidad al momento de recibir carga y a largo plazo se patentiza la vida útil de la mezcla, de igual forma reduce el costos en los mantenimientos de una infraestructura vial.

Los pavimentos son estructuras en las cuales están formadas las vías del tránsito terrestre, estan siendo integradas por varias capas de diferentes materiales que se encuentran superpuestas en un terreno modificado para suavizar el tránsito a su menor expresión [16], por otro lado, el material utilizado se compone de asfalto resistente y adhesivo el cual tiene una impermeabilidad estable para su rendimiento, [17].

Ante todo, se encuentran tipos de pavimentos: Pavimentos Asfálticos o Flexibles: Son aquéllos construidos con materiales asfálticos y materiales granulares; Pavimentos de Concreto o Rígidos: Pavimentos construidos con hormigón de cemento portland y materiales granulares; Otros: Adoquines, empedrados, suelo cemento Pavimentos Flexibles 0 Asfálticos. En general, están constituidos por una capa delgada de mezcla asfáltica construida sobre una capa de base y una capa de sub-base las que usualmente son de material 


\section{2}

granular. Estas capas descansan en una capa de suelo compactado, llamada subrasante. Ahora bien, una mezcla asfáltica, que se le denomina aglomerado está compuesta por diferentes materiales y minerales pétreos. Estas mezclas asfálticas pueden ser de varias temperaturas entre caliente y frio, con esto se logran varias opciones dependiendo de los usos que se le vallan a dar [18], [19]; entre ellas los ciclos de la temperatura ambiental que tienen influencia en el comportamiento de la mezcla asfáltica [20] y se constituyen como variables fundamentales para el diseño de las estructuras de pavimento flexibles [21-22], el cual segùn el autor representó un $32.89 \%$ [23].

Asimismo el asfalto se conoce, de ser un producto bituminoso semisólido, compuesto a base de hidrocarburos naturales que fueron destilados el cual consta de una proporción baja de productos volátiles, el asfalto se distingue por ser un material visco-elatoplástico, lo cual indica que su comportamiento tiene que ver con la temperatura y la frecuencia con la que se le apliquen cargas, bien sean elásticas de carácter recuperable o plásticas de carácter no recuperables [24]. Sellados sobre arena y sin ligante: Son aquellos donde se ven los adoquines de hormigón, adoquines de piedras, enlosados, pavimentos de madera, adoquines de granito. etc.

Se denomina un pavimento al conjunto de capas de un material seleccionado que recibe en forma directa las cargas de tránsito y estas a su vez se transmiten a los estratos inferiores de forma disipada, proporcionando una superficie de rodamiento que funcione de manera eficiente y agradable para los vehículos que en ella transitan [25]. Ante esto también se tiene que un pavimento flexible se denomina a aquellos pavimentos cuya estructura total se deflecta o flexiona dependiendo de las cargas que transitan sobre e., su uso es abundante fundamentalmente en zonas donde se presentan tráfico elevado, tales como autopistas, parqueaderos, vías de primer orden; este posee unas características especiales tales como su resistencia estructural, deformidad, durabilidad [26].

Para lograr un óptimo pavimento flexible se debe tener en cuenta ciertas variables de diseño tales como restricciones de tiempo, periodo de diseño, periodo de análisis, tránsito y confiabilidad, todas estas variables son claves a la hora de lograr un excelente diseño del pavimento flexible [27]. En este caso el uso de grano de caucho reciclado en el diseño de un pavimento flexible consiste en aplicar a nuestra capa asfáltica una proporción loable de nuestra materia prima reciclada como lo es el grano de caucho obtenido de la gran cantidad de residuos que encontramos en nuestro país de dicho material, al someterlo un proceso de optimización y separación de sus componentes obtenemos una fuente importante de material que al ser agregado a nuestra capa de rodadura de nuestro pavimento flexible, no solo estamos disminuyendo costos, también estamos alargando la vida útil del pavimento flexible ya que el caucho como tal da unas cualidades de flexibilidad las cuales encajan de manera acertada y uniforme en la mezcla que compone nuestra carpeta de rodadura que es la cual los vehículos van a transitar.

Ahora bien para la Sociedad Americana de Pruebas y Materiales (ASTM) por sus siglas en inglés, encargada de comprobar la capacidad que pueden resistir dichos materiales, tiene como definición a la mezcla de asfalto con grano de caucho reciclado tal como " una mescolanza asfáltica cementera compuesta de gran cantidad de partículas neumáticas recicladas, que a su vez van ligadas con un porcentajes de aditivos, en la cual el porcentaje del neumático reciclado corresponde a una cantidad no menor al $15 \%$ del total del peso de dicha mescolanza, la cual cuando reacciona con esta mezcla asfaltico cementera a altas 
temperaturas, logran que aumenten de tamaño las partículas de neumático" [11].

Por otro lado, la Administración Federal de Carreteras (FHWA) describe el grano de caucho como un caucho de llantas de desecho que ha sido procesado por molienda ambiente o métodos de granulación, que lo reduce a partículas que generalmente no superan los $4,75 \mathrm{~mm}$ (No. 4) de tamiz" [12]. Ante esto estos polímeros son utilizados para mejorar las mezclas y atribuir mejores propiedades y elevar los estándares de calidad, esta actividad conlleva algunas bondades en los diseños de las mezclas, entregando un alto desempeño en diferentes zonas climáticas $y$ entre las diferencias que han dado los estudios frente al pavimento tradicional se encuentran demostrados en los laboratorios a continuación: [28].

\begin{tabular}{|c|c|c|c|}
\hline Propiedad & $\begin{array}{c}\text { Asfalto } \\
\text { convencional }\end{array}$ & $\begin{array}{c}\text { Asfalto } \\
\text { modificado }\end{array}$ & Norma \\
\hline Penetración $(1 / 10 \mathrm{~mm}) 25^{\circ} \mathrm{C}$ & 88 & 71,0 & $\begin{array}{c}\text { Invías E-706 ASTM } \\
\text { D5-96 }\end{array}$ \\
\hline Ductilidad $(\mathrm{cm})$ & $>150$ & 41,7 & $\begin{array}{c}\text { Invias E-702 ASTM } \\
\text { D113-86 }\end{array}$ \\
\hline
\end{tabular}

Tabla 2. Caracterización fisicoquímica y morfológica de asfaltos modificados con material reciclado

\begin{tabular}{|c|c|c|c|}
\hline Propiedad & $\begin{array}{c}\text { Asfalto } \\
\text { convencional }\end{array}$ & $\begin{array}{c}\text { Asfalto } \\
\text { modificado }\end{array}$ & Norma \\
\hline Punto de ignición $\left({ }^{\circ} \mathrm{C}\right)$ & 290 & 295,0 & $\begin{array}{c}\text { Invías E-709 ASTM } \\
\text { D92-78 }\end{array}$ \\
\hline Punto de llama $\left({ }^{\circ} \mathrm{C}\right)$ & 330 & 317,0 & $\begin{array}{c}\text { Invias E-709 ASTM } \\
\text { D92-78 }\end{array}$ \\
\hline Peso especifico $(\mathrm{g} / \mathrm{cm} 3)$ & 1,009 & 1,039 & $\begin{array}{c}\text { Invias E-707 ASTM } \\
\text { D } 70-76\end{array}$ \\
\hline Punto de ablandamiento $\left({ }^{\circ} \mathrm{C}\right)$ & 48 & 54,7 & $\begin{array}{c}\text { Invias E-712 ASTM D } \\
36-76\end{array}$ \\
\hline $\begin{array}{c}\text { Ensayo de pérdida de masa } \\
\text { RTFOT }\end{array}$ & 1,0 & 0,40 & Invias E-720 \\
\hline
\end{tabular}

Por lo que se puede mostrar en lo que nombramos ahora, los datos que se arrojan las pruebas que se muestran de ahora hacia adelante tienen que ver únicamente con el asfalto convencional y con el de tipo alterado o modificado con un $14 \%$ de neumático y $1 \%$ de icopor. No obstante, también posee propiedades innatas de los aditivos pétreos como su solubilidad tal como se puede apreciar Solubilidad del asfalto en diferentes solventes también vemos que acá en la Tabla 3 se presentan los resultados obtenidos en los ensayos de solubilidad (expresados como gramos de asfalto que se solubilizan en 100 $\mathrm{mm}$ de solvente a $25^{\circ} \mathrm{C}$ ) realizados al asfalto del $\mathrm{CIB}$, el original y el modificado.

Tabla 3. Resultados de los ensayos de solubilidad para el asfalto convencional y el modificado

\begin{tabular}{cccc}
\hline Asfalto del CIB & Tolueno & Tricloroetileno & n-hexano \\
\hline Convencional & 96,5 & 90,8 & 82,3 \\
Modificado & 95,4 & 80,6 & 88,0 \\
\hline
\end{tabular}

Tabla 4. Resultados del análisis SARA realizado a los asfaltos del CIB, convencional y modificado

\begin{tabular}{cccccccc}
\hline Asfalto & Saturados & Aromáticos & Resinas & Asfaltenos & Maltenos & IC & IS \\
\hline Convencional & 25,16 & 37,62 & 28,83 & 8,39 & 91,61 & 0,50 & 4,93 \\
Modificado & 13,75 & 20,98 & 47,43 & 17,84 & 82,16 & 0,46 & 3,06 \\
\hline
\end{tabular}

Tabla 5. Resultados del análisis SARA realizado a los asfaltos del CIB, convencional y modificado

\begin{tabular}{cccccc}
\hline Asfalto & $\begin{array}{c}\text { Saturados/ } \\
\text { resinas }\end{array}$ & $\begin{array}{c}\text { Saturados/ } \\
\text { aromáticos }\end{array}$ & $\begin{array}{c}\text { Aromáticos/ } \\
\text { resinas }\end{array}$ & $\begin{array}{c}\text { Resinas/ } \\
\text { aromáticos }\end{array}$ & $\begin{array}{c}\text { Resinas/ } \\
\text { asfältenos }\end{array}$ \\
\hline $\begin{array}{c}\text { Convencional } \\
\text { Modificado }\end{array}$ & 0,87 & 0,67 & 1,30 & 0,77 & 3,43 \\
\hline
\end{tabular}

En base a estos estudios de sus propiedades podemos concluir con propiedad que el grano de caucho reciclado mejora propiedades como la Caracterización fisicoquímica y morfológica de asfaltos modificados con material reciclado [29], con esto se tiene que los resultados arrojados es de $1 \%$ con respecto a la modificación en su susceptibilidad térmica, a su vez,. La parte óptima en la modificación del asfalto convencional fue también de $1 \%$, y $14 \%$ de caucho y develo un compuesto estable, esto quiere decir que se tienen también propiedades físicas y químicas muy acordes para este tipo de mezcla con caucho MDC-2. Los asfaltos del CIB, convenida y modificado, se catalogan como tipo sol-gel, como la determinación química cumplida; igualmente se verificó la dependencia directa entre las propiedades fisicoquímicas del ligante y su estructura química. Sin embargo, los resultados indican 


\section{4}

que no se verificó un cambio significativo en la estructura química del ligante, pues el asfalto del CIB modificado obtenido es una mezcla física asfalto- polímero estable y homogénea. La cantidad de la llanta adicionada al asfalto determina sus características fisicoquímicas y, por ende, el desempeño de las mezclas asfálticas elaboradas con este ligante. Entre tanto, el tamaño de partícula de la llanta y el icopor cuando son añadidos al asfalto como modificadores influyen directamente en la homogeneidad estructural del ligante $\mathrm{y}$, por lo tanto, determinan la compatibilidad y estabilidad de las fases del ligante modificado [30].

\section{Materiales y métodos}

La presente investigación trata de un carácter descriptivo definido por [31] como un tipo de investigación que tiene como prioridad describir algunas particularidades fundamentales, por medio de fuentes secundarias con el fin de ordenar características, factores y variables de procedimiento realizados, a fin de generar una nueva información y buscar una interpretación correcta sobre esté. Además de ser descriptivo se puede decir que el proyecto realizado se enfatiza en la parte documental [30], debido a que la mayoría de información recopilada es a través de libros, sitios web y otras fuentes; en resumen, permite indagar cualquier tipo de estudio con la ayuda de los diferentes recursos existentes.

Resultados

Tabla 6. Impacto sobre la utilización del grano de caucho reciclado para la obtención de pavimentos flexibles

\begin{tabular}{|c|c|}
\hline \multicolumn{2}{|c|}{ Impacto sobre la utilización del grano de caucho reciclado para la obtención de pavimentos flexibles } \\
\hline impacto ambiental & $\begin{array}{l}\text { El desecho a nivel mundial de llantas es muy elevado generando un impacto negativo alto } \\
\text { en el medio ambiente. Las llantas son uno de los elementos que más se desechan en el } \\
\text { mundo y no son video degradables (no pueden descomponerse). } \\
\text { Las llantas son un sitio pendenciar de incoación de mosquito en época de lluvia, } \\
\text { contaminan visualmente el ambiente además de ser desechadas al aire libre están propensas } \\
\text { a incendios, además la principal forma de deshacerse de estos objetos es quemarlos que trae } \\
\text { problemas no solo de contaminación ambiental sino de salud. } \\
\text { La utilización de GCR para modificar las mezclas asfálticas cuenta con grandes beneficios } \\
\text { para la estructura vial, además de sus beneficios medio ambientales debido al } \\
\text { aprovechamiento de llantas usadas los cuales son componentes de contaminación a gran } \\
\text { escala debido a su corta vida útil. }\end{array}$ \\
\hline impacto económico & $\begin{array}{l}\text { La alternativa de utilización de llantas usadas para el asfalto resultó una opción bastante } \\
\text { costosa para las empresas. Según la asociación nacional de asfalto de Estados Unidos el } \\
\text { asfalto con un reemplazo del } 25 \% \text { de llantas usadas presenta una durabilidad más alta y } \\
\text { ofrece un agarre superior a los vehículos en la via. Sin embargo, el análisis económico de } \\
\text { este proyecto determinó que en un término de } 5 \text { años la incorporación de GCR a la } \\
\text { producción de asfaltos generaría pérdidas económicas. No obstante, actualmente la norma } \\
\text { distrital emitida exige a los oferentes de la licitación el reemplazo del } 25 \% \text { pues representa } \\
\text { menos costos de reparación a futuro. } \\
\text { La producción de asfalto como alternativa para aprovechamiento de las llantas en su etapa } \\
\text { de fin de vida puede ser viable en la medida en que se prioricen las politicas de estado y de } \\
\text { la alcaldia orientadas al desarrollo de la infraestructura vial y la implementación de GCR } \\
\text { como normativa en la mezcla asfáltica para cualquier tipo de via así como en los programas } \\
\text { de mantenimiento tanto de las nuevas vías como de las existentes esto, debido también al } \\
\text { costo elevado que tiene el proceso para la mezcla asfáltica con GCR en comparación con la } \\
\text { mezela asfáltica tradicional. Esta normativa podria generar la creación de empresas que se } \\
\text { encarguen de producir esta mezcla con GCR, creando más competitividad y reduciendo } \\
\text { costos de producción y finalmente del producto. También cabe resaltar que el si bien en } \\
\text { cinco años la rentabilidad de esta alternativa podria ser negativa, puede igual resultar siendo } \\
\text { una buena inversión a largo plazo pues, al ser vías mucho más compactas. duraderas y de } \\
\text { mejor tracción, se van a reducir los costos de mantenimiento (repavimentación). }\end{array}$ \\
\hline $\mathbf{x x x x}$ & $\begin{array}{l}\text { El manejo inadecuado de cualquier tipo de residuo genera impactos en la comunidad como } \\
\text { en la salud, ambiente y la economia, y no deja de ser una problemática social para todos, la } \\
\text { explotación y comercialización de grano de caucho reciclado en general ayudaría a la } \\
\text { industrialización y transformación de materias primas. } \\
\text { La implementación del grano de caucho reciclado para la obtención de nuevos pavimentos } \\
\text { flexibles es una idea mui concertante que traerá a la comunidad impactos muy viables ya } \\
\text { que estamos reutilizando estas llantas que contaminan al ecosistema al deshacerse de ellas o } \\
\text { quemarlas, entonces este proyecto de la obtención del grano de caucho reciclado es muy } \\
\text { viable, nos beneficia a todos. }\end{array}$ \\
\hline
\end{tabular}


La fabricación de un pavimento flexible utilizando una mezcla asfáltica con grano de caucho reciclado resulta ser muy costosa pero la utilización de este pavimento tiene muy buen rendimiento al ser mucho más compacta duradera y de mejor tracción en cuanto a cargas pasadas, entonces en si hablamos de la gestión del pavimento van a mejorar los costos al no invertir tanto en mantenimiento de la infraestructura vial, que son los problemas más comunes. Además, al reciclar las llantas ya que estas, son las que más se desechan se lograra mejorar nuestro ambiente, la implementación de un pavimento con GCR es muy prometedor a futuro debido a que se puede lograr establecer los costos económicos de tal manera que si genera más producción y se busca ser pioneros a nivel mundial este se reduce.

\section{Conclusiones}

En Colombia, existe una gran problemática ambiental y social debido a la mala manipulación que se le da a la disposición final de las llantas, es decir que la adaptación de este recurso y su aplicación en pavimentos flexibles no ha sido el más adecuado, y esto es debido en gran parte a la falta de conocimiento del proceso de la implementación e incitación del uso de este ligante como es el (GCR) en mezclas asfálticas. Las utilidades que dan el uso de este tipo de técnicas a nivel monetario se pueden ver a plazos no muy lejanos, pero a su vez no tan cortos, ya que al cambiar los componentes como los agregados finos por material reciclado, aumenta la vida útil del pavimento flexible lo que permite que el mantenimientos de la infraestructura se extienda a mayor tiempo; según el estudio recopilados por investigadores sobre el tema, es notable la viabilidad de implementación de asfalto con grano de caucho reciclado, y comparando su proceso y eficiencia con una mezcla convencional, se consideró que el costo de la implementación de mezclas de asfalto modificado con (GCR) es aproximadamente mayor su costo que la de una mezcla de asfalto convencional, pero a su vez, es evidente que lo anterior sea compensado con la reducción de los costos que genera el mantenimiento de una vía con mezcla de asfalto convencional.

Finalmente, la recopilación de información encontrada sobre esta tecnología a nivel internacional indica avances favorables y de gran importancia, lo que ha permitido su ejecución en varios países quienes durante años se concentra en buscar mejoramientos en los procesos de producción de mezclas asfálticas; En consecuencia a la falta de conocimiento, en Colombia la aplicación de esta tecnología no ha sido muy práctico, pero ha habido diferentes instituciones que han podido implementar esta tecnología con gran efectividad.

\section{Referencias}

[1] Y.V. Lopez-Cabrejos, "Influencia del reciclado de pavimento flexible para mejorar la conservación vial entre calles 6 y 7 de Ventanilla Alta, 2018", tesis de pregrado, Universidad César Vallejo, Callao, Perú, 2018

[2] G.J. Pérez, "La La infraestructura del transporte vial y la movilización de carga en Colombia", Banco de la República 2005. [En línea]. Disponible en: http://www.banrep.gov. co/docum/Lectura_finanzas/pdf/DTSER-64. pdf

[3] H.A. Rondon-Quintana y F.A. Reyes-Lizcano, "Pavimentos. Materiales, construcción y diseño", Cúcuta: ECOE Ediciones, 2015

[4] ONI, EcuRed, "Pavimento flexible", EcuRed. [En línea]. Disponible en: https://www.ecured. cu/Pavimento_flexible

[5] J.E. Forigua-Orjuela y E. Pedraza-Díaz, "Diseño de mezclas asfálticas modificadas 


\section{6}

mediante la adición de desperdicios plásticos", tesis de pregrado, Universidad Católica de Colombia, Bogotá, Colombia, 2014

[6] E.I. Guio-Vargas y H.M. Sánchez-Abril, "Mezclas asfálticas recicladas y su uso en capas granulares para pavimentos", Revista Colombiana de Materiales no. 5, pp. 382-388, 2013

[7] ConcienciaEco, "Que es el reciclaje," Revista digital ConcienciaEco, 2012. [En línea]. Disponible en: https://www.concienciaeco. com/2012/08/21/que-es-el-reciclaje/2012/

[8] M. Servin, "Llanta inmortales" EUREKA, 1999. [En línea]. Disponible en: https://www. jornada.com.mx/1999/07/05/cien-eureka.html

[9] G. Botasso, A.Segura, "Mezclas asfálticas ecológicas para la vialidad urbana", Revista de Obras Públicas: Organo profesional de los ingenieros de caminos, canales y puertos, no. 3593, pp. 82-87 2017

[10] P. Cardona-Urrutia, "Estudio de factibilidad para la creación de una planta de producción de granos de caucho (GCR) mediante el reciclaje de llantas fuera de uso", tesis de pregrado. Universidad Tecnológica de Pereria, Risaralda, Colombia, 2016

[11] C.A. Correa- Lesmes, "Implementación de mezcla asfaltica modificada con granulo de caucho en el barrio San Carlos de la localidad de tunjuelito", trabajo de especialización. Universidad Militar Nueva Granada, Bogotá, Colombia, 2016.

[12] C.M. Diaz-Claros y L.C. Castro-Celis, "Implementación del grano de caucho reciclado (gcr) proveniente de llantas usadas para mejorar las mezclas asfálticas y garantizar pavimentos sostenibles en Bogotá", Universidad Santo Tomás. Bogotá, Colombia, 2017.
[13]Michelin.com.ec. "Todo sobre llantas". Michelin.(s.f) [En línea]. Disponible en: https:// www.michelin.com.ec/todo-sobre-autos/masinfo/Michelin-la-llanta-que-dura-dura-y-dura

[14] J. Ramoneda, "Mal estado de vías en Colombia generan $35 \%$ en sobrecostos a transportadores" elpais.com.co, 2013. [En línea]. Disponible en: https://www.elpais.com.co/economia/malestado-de-vias-en- colombia-generan-35- ensobrecostos-a- transportadores.html

[15] V.A Ramirez-Garzon, "Creación de una empresa dedicada al reciclaje de llantas a través de su trituración", tesis de pregrado. Universidad EAN. Bogotá, Colombia, 2012

[16] Ministerio de Transporte, "Manual de diseño de pavimentos de concreto para vìas con bajos, medios y altos volúmenes de tránsito", Bogotá, Colombia: Instituto Colombiano de Productores de Cemento

[17] G.J. Huertas-Cadena y J.D. Cazar-Ruiz, "Diseño de un pavimento flexible adicionando tereftalato de polietileno como material constitutivo junto con ligante asfáltico AC-20", tesis de pregrado. Universidad de las Fuerzas Armadas ESPE. Latacunga, Ecuador, 2014

[18]Ministrio de Fomento, "Pliego de Prescripciones Técnicas Generales", Gobierno de españa. 2014. [En línea]. Disponible en: https://www. fomento.gob.es/MFOM.CP.Web/handlers/ pdfhandler.ashx?idpub=ICW020

[19]ASEFMA, "Las mezclas bituminosas empleadas en tramos de carreteras en túneles contribuyen significativamente a la seguridad vial". Asociación española de fabricantes de mezcla asflatica, [En línea]. Disponible en: http://www.asefma.es/

[20] C.H. Higuera-Sandoval, "Efecto de la temperatura en el módulo dinámico del 
cemento asfáltico y la mezcla asfáltica - caso de Boyacá", Respuestas, vol. 21, no. 1, pp. 108119, ene. 2016

[21] C.R. Sanabria Sanabria y C.H. Higuera Sandoval, "Comportamiento de una mezcla asfáltica MDC-19 bajo los ciclos de temperatura ambiente en la ciudad de Tunja, Colombia", Respuestas, vol. 24, n. ${ }^{\circ}$ 1, pp. 56-64, ene. 2019

[22] R.A García-León, E.F Solano y A. Acevedo, "Caracterización térmica de mezclas de arcillas utilizadas en la fabricación de productos de mampostería para la construcción", Revista Tecnologías de Avanzada, vol. 1, no. 31, 2018

[23] R.J. Gallardo Amaya, L. J. Quintero Lemus, y O. A. Cuanalo Campos, "Caracterización de la tipología de fallos presentados en los pavimentos de la ciudad de Ocaña Norte de Santander", Revista Ingenio, vol. 13, n. ${ }^{\circ}$ 1, pp. 57-64, jun. 2017

[24] P. Garnica-Anguas, J.A. Gómez-López y J.A. Sesma-Martinez "Mecánica de materiales". Publicación Técnica No. 197, 2005. [En línea]. Disponible en: https://www.imt.mx/archivos/ Publicaciones/PublicacionTecnica/pt197.pdf

[25] E. MBA-Lozano y R. Tabares-Gonzalez "Diagnóstico de via existente y diseño del pavimento flexible de la via nueva mediante parámetros obtenidos del estudio en fase I de la via acceso al barrio ciudadela del café - vía la badea", tesis de especialización. Universidad Nacional de Colombia, Sede Manizales, Manizales, Colombia. 2005

[26] H.A. Rondon y F.A. Reyes-Lizcano, "Metodologías de diseño de pavimentos flexibles: Tendencias, alcances y limitaciones" Ciencia e Ingeniería Neogranadina, vol. 17, no. 2, pp. 41-65. 2007

[27] AASHTO, "Guide for Design of Pavement
Structures 1993". United State: American Association of State Highway and Transportation Officials. 1993

[28] F.L. Castaño-Martínez, J.M. Herrera- Betín, J.N. Gómez-Sáenz y F.A. Reyes- Lizcano "Análisis cualitativo del flujo de agua de infiltración para el control del drenaje de una estructura de pavimento flexible en la ciudad de Bogotá D.C." Portal de Revistas Académicas, vol. 11, no. 22, 2009

[29]A.S. Figueroa-Infante, E.B. Fonseca- Santanilla y F.A. Reyes-Lizcano, "Caracterización fisicoquímica y morfológica de asfaltos modificados con material reciclado", Ingeniería y Universidad, vol. 13, no. 1, pp. 45-70, enerojunio, 2009

[30] S. Infante, B. Santanilla and A. Lizcano, "Caracterización fisicoquímica y morfológica de asfaltos modificados con material reciclado". Ingeniería y Universidad, vol. 13, no 1, pp. 4570, enero-junio, 2009

[31] B. Giraldo, "Marco metodológico", En: Metodología de la Investigación, 2013 